Research article

\title{
Morphological, histochemical, and interstitial pressure changes in the tibialis anterior muscle before and after aortofemoral bypass in patients with peripheral arterial occlusive disease Maria Albani*1, Angelos Megalopoulos², Dimitris Kiskinis' ${ }^{2}$, Sotirios A Parashos ${ }^{4}$, Nikolaos Grigoriadis ${ }^{3}$ and Olympia Guiba-Tziampiri ${ }^{1}$
}

\begin{abstract}
Address: ${ }^{1}$ Department of Physiology, Medical School, Aristotle University of Thessaloniki, Thessaloniki 54006, Greece, ${ }^{2}$ Dept of Surgery, Medical School, Aristotle University of Thessaloniki, Thessaloniki 54006, Greece, ${ }^{3}$ Dept of Neurology, Medical School, Aristotle University of Thessaloniki, Thessaloniki 54006, Greece and ${ }^{4}$ Minneapolis Clinic of Neurology, 6330 France Avenue, Edina, Minnesota, 55435, U.S.A
\end{abstract}

E-mail: Maria Albani* - albani@med.auth.gr; Angelos Megalopoulos - Dorodemo@med.auth.gr; Dimitris Kiskinis - insomnia@otenet.gr; Sotirios A Parashos - paras001@tc.umn.edu; Nikolaos Grigoriadis - grigoria@med.auth.gr; Olympia Guiba-Tziampiri - guiba@ccf.auth.gr ${ }^{*}$ Corresponding author

Published: 25 February 2002

BMC Musculoskeletal Disorders 2002, 3:8
Received: II October 200I

Accepted: 25 February 2002

This article is available from: http://www.biomedcentral.com/I47I-2474/3/8

(c) 2002 Albani et al; licensee BioMed Central Ltd. Verbatim copying and redistribution of this article are permitted in any medium for any purpose, provided this notice is preserved along with the article's original URL.

\begin{abstract}
Background: Morphological and electrophysiological studies of ischemic muscles in peripheral arterial disease disclosed evidence of denervation and fibre atrophy. The purpose of the present study is to describe morphological changes in ischemic muscles before and after reperfusion surgery in patients with peripheral occlusive arterial disease, and to provide an insight into the effect of reperfusion on the histochemistry of the reperfused muscle.

Methods: Muscle biopsies were obtained from the tibialis anterior of 9 patients with chronic peripheral arterial occlusive disease of the lower extremities, before and after aortofemoral bypass, in order to evaluate the extent and type of muscle fibre changes during ischemia and after revascularization. Fibre type content and muscle fibre areas were quantified using standard histological and histochemical methods and morphometric analysis. Each patient underwent concentric needle electromyography, nerve conduction velocity studies, and interstitial pressure measurements.

Results: Preoperatively all patients showed muscle fibre atrophy of both types, type II fibre area being more affected. The mean fibre cross sectional area of type I was $3,745 \mu \mathrm{m}^{2}$ and of type II 4,654 $\mu \mathrm{m}^{2}$. Fibretype grouping, great variation in fibre size and angular fibres were indicative of chronic dennervationreinnervation, in the absence of any clinical evidence of a neuropathic process. Seven days after the reperfusion the areas of both fibre types were even more reduced, being $3,086 \mu \mathrm{m}^{2}$ for type I and 4,009 $\mu \mathrm{m}^{2}$ for type II, the proportion of type I fibres, and the interstitial pressure of tibialis anterior were increased.

Conclusions: The findings suggest that chronic ischemia of the leg muscles causes compensatory histochemical changes in muscle fibres resulting from muscle hypoxia, and chronic dennervationreinnervation changes, resulting possibly from ischemic neuropathy. Reperfusion seems to bring the oxidative capacity of the previously ischemic muscle closer to normal.
\end{abstract}

\section{Background}

Structural and functional adaptations take place in work- ing and resting muscles when the blood flow is insufficient to satisfy energy requirements [1-3]. Partial 
ischemia for short periods of time may cause cell damage in humans $[4,5]$, while metabolic changes in leg muscles have been reported after 16 hours of ischemia [6]. Morphological and electrophysiologic studies of ischemic muscles in peripheral occlusive arterial disease disclosed evidence of denervation and type II fibre atrophy [7-9]. Several studies have demonstrated an increase in the oxidative capacity of ischemic muscles in patients with atherosclerotic peripheral occlusive arterial disease $[8,10-$ 12] while other authors reported reduced oxidative capacity in leg muscles of patients with intermittent claudication $[13,14]$.

The crucial role of increased blood flow in striated muscles after an ischemic period has been studied extensively in the heart muscle. Recent publications $[15,16]$ have shown biochemical, morphological and ultra structural changes in the heart muscle after reperfusion in experimentally induced prolonged global ischemia or after the use of free oxygen radical inhibitors.

Although biochemical changes occurring in other organs during reperfusion following ischemia have been described in numerous studies [17-21], there is hardly any information about changes in human muscle fibres during reperfusion after bypass operations. The purpose of the present study is to identify the histochemical profile of ischemic skeletal muscles before and after the revascularization operation in patients with peripheral occlusive arterial disease.

\section{Materials and Methods Subjects}

Nine $64 \pm 12$ year-old men with atherosclerotic lesions at the aortoiliac level (Fontaine stage II) were investigated. None of them showed clinical signs of peripheral neuropathy, and any history of diabetes mellitus. All patients were submitted to a reconstructive surgical procedure, which consisted of uni- or bilateral aortofemoral bypass grafting, and were given $100 \mathrm{mg}$ acetylsalicylic acid per day as postoperative treatment. The patients were informed on the nature of the study, with the possible risks of the procedures, and they gave consent prior to inclusion in the study. The Human Subjects Committee of the Aristotle University of Thessaloniki approved the experimental protocol.

\section{Procedures}

Electrophysiologic studies

All patients underwent standard electromyographic examination of both lower extremities, before the first biopsy to exclude peripheral neuropathy. Motor nerve conduction velocities with corresponding F-waves of the posterior tibial and peroneal nerves and sensory nerve conduction velocities of the sural nerves were obtained bilaterally, using standard technique, and a Neuropack $2^{\circledR}$ (Nihon Kohden). Concentric needle electromyographic examination was limited to the tibialis anterior, extensor digitorum brevis and abductor hallucis brevis bilaterally. None of the patients showed electrophysiologic evidence of a peripheral neuropathy.

\section{Muscle Biopsy}

Two tissue samples were obtained from each patient during each biopsy under local anaesthesia (1\% lidocaine), from the tibialis anterior muscle. The samples were dissected out in blocks of $5 \times 5 \times 5 \mathrm{~mm}^{3}$, were taken from a well-defined portion of the muscle belly, to a depth of about $2 \mathrm{~cm}$ beneath the fascia, at the half distance between the ankle and the knee. The first biopsy was taken during the reconstructive surgery procedure and the second biopsy 7 days after the operation. Each sample was then frozen in melting isopentane $\left(-60^{\circ} \mathrm{C}\right)$ cooled in liquid nitrogen, and stored in a freezer $\left(-80^{\circ} \mathrm{C}\right)$.

\section{Intramuscular pressure measurement}

Muscle compartmental pressure was measured pre- and postoperatively, at the $1^{\text {st }} \& 7^{\text {th }}$ postoperative day, by inserting a special sterile 18 gauge side ported needle $6.4 \mathrm{~cm}$ long, in the tibialis anterior muscle, which was connected to the Stryker intra-compartmental pressure monitor system (Stryker, 295-1 Pressure), a hand held monitor system specifically designed for measuring tissue fluid pressures.

Table I: Fibre type areas, proportions and age of subjects as reported by other authors

\begin{tabular}{lccccc}
\hline Authors & Type I area $\left(\mu \mathrm{m}^{2}\right)$ & Type I (\%) & Type II area $\left(\mu \mathrm{m}^{2}\right)$ & Type II (\%) & Age and sex (yrs - M/F) \\
\hline & & & & & \\
Jakobsson F et al [22] & $4,050 \pm 8,900$ & $84 \pm 9$ & $5,700 \pm 1970$ & $15 \pm 8$ & $70, \mathrm{M \& F}$ \\
Angquist et al [23] & $5,407.86$ & 74 & $7,386.06$ & 26 & $59, \mathrm{M} 47, \mathrm{~F}$ \\
Friden et al [24] & $5,430 \pm 883$ & 69 & $8,132 \pm 1747$ & 31 & $26, \mathrm{M}$ \\
Henriksson-Larsen et al [13] & 5,024 & 70 & $7,234.56$ & 30 & $59, \mathrm{M} 47, \mathrm{~F}$ \\
Sjøstrøm et al [8] & & & & & \\
\end{tabular}

values are means $\pm s d$ 


\section{Histology and Enzyme histochemistry}

Transverse serial sections of $9 \mu \mathrm{m}$ - thick of each sample were cut in a cryostat microtome at $-20^{\circ} \mathrm{C}$. The sections were processed with eosin-hematoxylin, hematoxylin-van Gieson for routine histologic examination; with succinic dehydrogenase (SDH) and NADH-trichrome reductase [22] for oxidative enzyme activity [21]; with myosin-ATPase for fibre typing [22]; and with periodic acid-Schiff ((PAS) for glycogen [22].

\section{Morphometry}

Morphometric parameters were determined by projecting the microscope slides (Zeiss) via a camera lucida onto a calibrated grid (Huston Instrument TG 1011 digitizer) linked to a desktop computer. A program was developed in GW-BASIC for digitation and further calculations. Fibre-type cross-sectional area and fibre type proportion were determined by counting 200 contiguous fibres of the central part of each tissue sample.

\section{Statistical methods}

Continuous data were reported as mean value \pm standard deviation and categorical data as percentages. Paired Student's test was used for comparing differences between the mean values before and after reperfusion, and chi-square was used to compare the differences between the fibretype proportions before and after the reperfusion. Differences were considered significant at $\mathrm{P}$ values $<0.05$.

\section{Results}

\section{Histological examination}

First biopsy (before bypass grafting)

The routine histologic examination revealed pericellular leucocyte infiltration between and within degenerating fibre, and necrotic muscle fibres (Fig. 1a and 1b), regenerated muscle fibres, and fibre size diversity (Fig. 1b and 1c). All patients showed muscle fibre atrophy, which was more pronounced in type II fibres, and great fibre size diversity; the mean area of type II fibres was $4,654 \pm 2,626 \mu \mathrm{m}^{2}$, a $18-43 \%$ reduction when compared to previous reports on healthy subjects of similar age (Table 1). Type I fibre size was $3,745 \pm 2,094 \mu \mathrm{m}^{2}$, a value which is also $7.5-31 \%$ less than the reported value for healthy subjects of similar age (Table 1). The mean proportion of type I fibres was 58.3 $\%$ and of type II was $41.7 \%$. NADH-tetrazolium reductase staining demonstrated $55.6 \%$ of oxidative fibres and 44.4 $\%$ of nonoxidative (Table 2). Abnormalities typical for denervation and reinnervation, i.e., small angular fibres (Fig. 1b and 1c) and small areas of fibre-type grouping (Fig. 1d) were seen in all samples.

\section{Second Biopsy (7 days after bypass grafting)}

Seven days after the aortofemoral bypass grafting, the main morphological muscle fibre characteristics remained unchanged (Fig. 2). Muscle fibre atrophy was
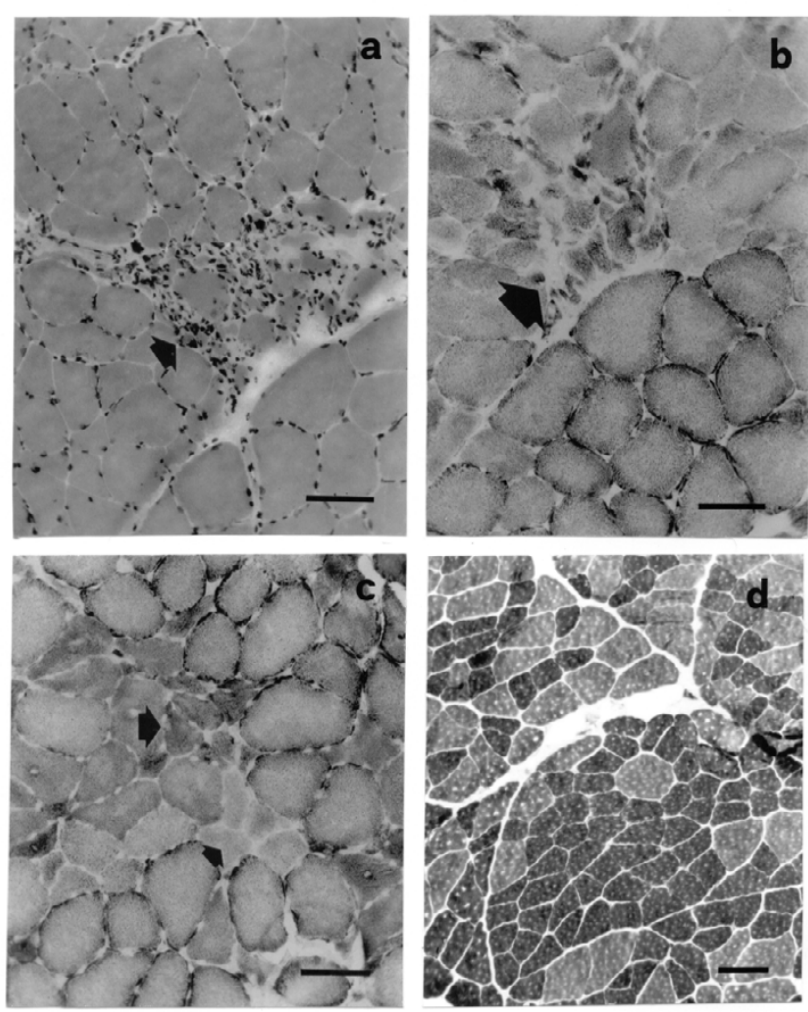

\section{Figure I}

Micrographs from sections of tibialis anterior muscle from patients with peripheral occlusive disease before reperfusion procedure (calibration: $100 \mu \mathrm{m}$ ). (a) Eosin-hematoxylin. (b) $\mathrm{SDH}$; phagocytosis and necrotic muscle fibres (arrows). (c) Myosin-ATPase, acid preincubation; small groups of atrophic angular muscle fibres (arrows), and fibre size diversity. (d) $\mathrm{NADH}$; small areas of fibre-type grouping.

again observed (Fig. 2a and 2b; Tables 2, 3). PAS staining did not show any obvious differences in muscle fibres before and after the reperfusion (data not shown). The mean fibre cross-sectional area, reduced for both fibre types, was $4,008 \pm 1917 \mu \mathrm{m}^{2}$ for type II, and 3,085 \pm 1340 am for type I fibres. The high standard deviation values of all area measurements both before and after the repair surgery procedure suggests a great variation of fibre size, which reflects the presence of many atrophic and regenerating muscle fibres among the normal ones. The proportion of type II fibres was decreased to $33.8 \%$ while that of type I fibres was increased to $66.2 \%$, although not statistically significant. Abnormalities typical for denervation and reinnervation were again seen in all samples (Fig. 2).

\section{Interstitial pressure measurements}

The interstitial pressure was $6.5 \pm 3.3 \mathrm{~mm} \mathrm{Hg}$ in the tibialis anterior of ischemic limbs before the reconstructive surgery procedure, but was increased to $10.30 \pm 5 \mathrm{~mm} \mathrm{Hg}$ on the $1^{\text {st }}$ postoperative day, and to $14.38 \pm 9.8 \mathrm{~mm} \mathrm{Hg}$ 
Table 2: Muscle fibre cross-sectional areas and fibre type proportions of tibialis anterior biopsy samples before and after the reconstructive surgical procedure (values are means $\pm s d$ )

\begin{tabular}{|c|c|c|c|}
\hline & Before & After & Significance \\
\hline \multicolumn{4}{|c|}{ OXIDATIVE FIBRES } \\
\hline Area $\left(\mu \mathrm{m}^{2}\right)$ & $3546.8 \pm 1413$ & $3264.8 \pm 769$ & $P<0.00 I^{* *}$ \\
\hline Fibre proportion & $55.7 \%$ & $62.5 \%$ & $N S^{* *}$ \\
\hline \multicolumn{4}{|c|}{ NON OXIDATIVE FIBRES } \\
\hline Area $\left(\mu m^{2}\right)$ & $4003.5 \pm 1388$ & $3771.3 \pm 1238$ & $P<0.05^{* *}$ \\
\hline Fibre proportion & $44 \%$ & $37.5 \%$ & $N S^{* *}$ \\
\hline
\end{tabular}

* Student's t-test ${ }^{* *}$ Chi-square NS: not statistically significant

Table 3: Morphometric data of tibialis anterior muscle fibres (mean \pm SD), in the muscle biopsy samples before and after reperfusion.

\begin{tabular}{lccc}
\hline & Before & After & Significance \\
\hline TYPE I FIBRES & & & \\
Area $\left(\mu \mathrm{m}^{2}\right)$ & $3,745 \pm 2,094$ & $3,086 \pm 1,340$ & $\mathrm{P}<0.00 I^{* * *}$ \\
Fibre proportion & $58.2 \%$ & $66.2 \%$ & $\mathrm{NS} *$ \\
TYPE II FIBRES & & $4,009 \pm 1,917$ & $\mathrm{P}<0.00 I^{* * *}$ \\
Area $\left(\mu \mathrm{m}^{2}\right)$ & $4,654.5 \pm 2626$ & $33.8 \%$ & $\mathrm{NS} S^{* *}$ \\
Fibre proportion & $41.7 \%$ & & \\
\hline
\end{tabular}

* Student's t-test ${ }^{* *}$ Chi-square NS: not statistically significant

on the $7^{\text {th }}$ postoperative day. Two-tailed paired t-test showed difference only between the preoperative and postoperative values for $\mathrm{P}<0.05$; no statistically significant difference was found between the $1^{\text {st }}$ and the $7^{\text {th }}$ postoperative day values.

\section{Discussion}

The main morphological characteristics of ischemic muscles in peripheral occlusive arterial disease patients with peripheral occlusive arterial disease observed in the present study are similar to those reported by Sjøstrøm et al [8]. The presence of muscle fibre grouping in all biopsies suggests a process of chronic dennervation-reinnervation, a possibility previously disputed. The question of whether fibre-type grouping and nerve-ending degeneration might be age-related rather than the result of ischemia is still open to debate. The effect of ischemia and reperfusion on motor nerves has been described in humans $[9,27]$ and in experimental animal models [28-32], nevertheless the underlying mechanism is incompletely understood. During reperfusion of the acutely ischemic tibialis anterior of rabbits, the deep peroneal nerve's conduction was impaired and the action potential was abolished [29]. Tourniquet ischemia for 20 min prevents paw plantar flexion following stimulation of the tibial nerve [31], and causes changes in sympathetic or parasympathetic activity, when applied for longer periods [30]. The electromyographic findings of the present study, i.e. normal conduction velocities with evidence of chronic dennervation-reinnervation are in agreement with previous reports in patients with peripheral occlusive arterial disease [9], and would be consistent with the notion of a parallel neuropathic process, likely ischemic in etiology [27]. The fact that no overt neuropathy was apparent in our patients, either on clinical examination, or on nerve conduction testing, is most likely the result of the relatively early peripheral occlusive arterial disease stage of our patients.

Groups of small regenerated muscle fibres were noted in this study on light microscope both before and after 7 days reperfusion with no change in appearance, whereas Karpati et al [33] on electron microscope after 7 days of experimentally induced ischemia on Sprague Dawley rats observed mitochondrial debris and large membrane-lined space. The same authors reported no change in the appearance of regenerating fibres found in ischemic muscle for up to 3 months. In this study the presence of regenerated and atrophic muscle fibres is also illustrated by the 

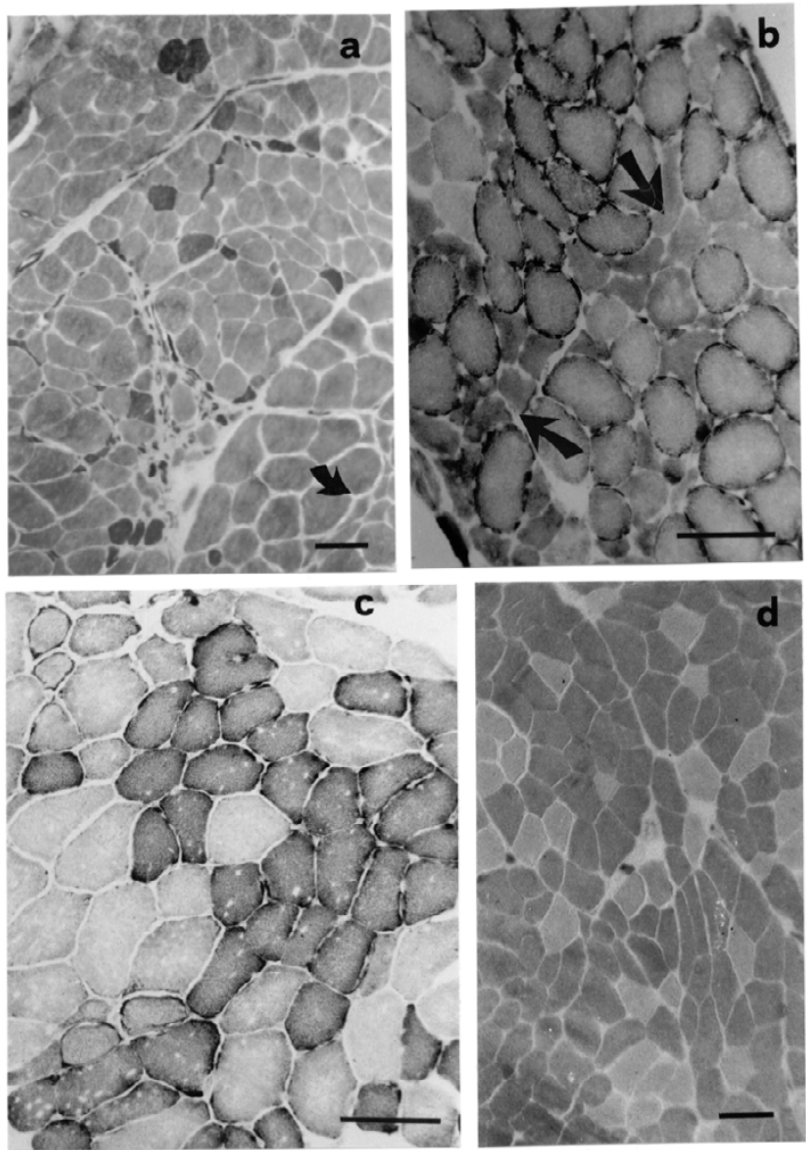

Figure 2

Micrographs from sections of tibialis anterior muscle from patients with peripheral occlusive disease after reperfusion procedure (calibration: $70 \mu \mathrm{m}$ ). (a) Myosin-ATPase, acid preincubation, (b) NADH; small angular atrophic muscle fibres of both types in small groups or dispersed (arrows). (c) $\mathrm{NADH}$. (d) ATPase; fibre-type grouping.

heterogeneity found within both fibre populations. Similar findings were reported by Sjøstrøm [8] who suggested that these changes were due either to loss of large efferent nerves, and possibly of anterior horn cells, or to the cumulative effect of incidental diseases.

Ischemia affects each muscle fibre type in different ways according to its particular metabolic and functional properties. The type I predominance found in our study, as well as the muscle fibre areas of tibialis anterior muscle are in accordance with the findings of other authors of age-matched human subjects $[24,34,35]$. However, as a result of conflicting reports regarding muscle oxidative capacity in patients with peripheral occlusive arterial disease $[1-3,8,10,11,13,14,21,23,34]$ the relationship between local pathology and clinical symptomatology remains elusive. Jennische [36] found a selective vulnerability of the fast glycolytic fibres to experimental ischemia in rats. By contrast, slow-oxidative fibres were spared. The author attributed the difference to the higher content of free-radical scavenger compounds in the more tolerant fibres, and to their different capability for calcium uptake. Other investigators reported an increase in mitochondrial volume in chronically ischemic muscles [25,32], while, in an apparent contradiction, decreased muscle oxidative capacity has been reported in patients with intermittent claudication [13], and decreased dehydrogenase activity following 6 hours of ischemia in dogs [37].

A possible explanation to this discrepancy was given by Clyne et al [38], who stated that during the initial stages of ischemia skeletal muscle tries to compensate for the oxygen deficiency, while at later stages as blood flow is further decreased and functional demands are increased, it looses the functional adaptations.
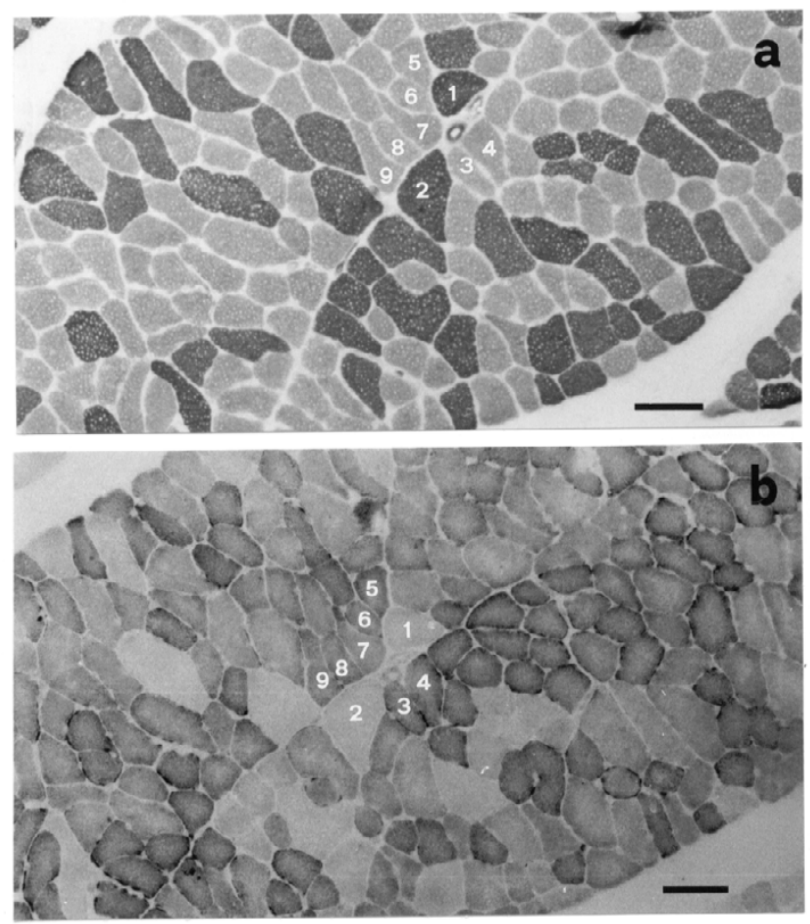

Figure 3

Micrographs from serial adjacent section of the same field (each muscle fibre stained differently in $a$ and $b$ is marked with a number) of rectus abdominis muscle (used as control) before the reconstructive surgery (calibration I50 $\mu \mathrm{m}$ ). (a) Myosin-ATPase (acid preincubation), (b) NADH; normal appearance. 


\section{Conclusions}

The morphometric, histological and histochemical observations of our study suggest that type I fibres are at least somewhat vulnerable to ischemia, although not to the same degree as type II fibres. The proportion of type I fibres of the ischemic tibialis anterior increased to $66.2 \%$ after reperfusion (Table 3 ), a number closer to that reported for normal subjects $[8,13,22-24]$, whereas the proportion of type II fibres proportionally decreased (Table 3), eventhough these changes in proportions of fibre types were not statistically significant. The mean cross-sectional area of both muscle fibre types was decreased after reperfusion, $17.6 \%$ for type I and $13.8 \%$ for type II, conceivably as a result of a postbypass efflux of intracellular compounds to the interstitial space and a subsequently increased interstitial fluid volume. Such statistically significant increase in interstitial fluid volume would also explain the observed postoperative increase in the interstitial fluid pressure.

Our findings indicate that in patients with peripheral occlusive arterial disease at the aortoiliac level, both muscles and nerves are affected. Chronic dennervation-reinervation mechanisms may account for the fibre type grouping, while reperfusion may favourably affect the oxidative properties of chronically ischemic muscles.

\section{Declaration of competing interests}

None declared.

\section{Acknowledgements}

The authors thank Dora Kapoucranidou for her technical assistance. We also thank Professor Olga Hudlicka for her comments on the manuscript.

\section{References}

I. Elander A, Idstrom JP, Holm S, Schersten T, Bylund-Fellenius AC: Metabolic adaptation to reduced muscle blood flow. II. Mechanisms and beneficial effects. Am J Physiol I 985, 249:E70-6

2. Elander A, Idstrom JP, Schersten T, Bylund-Fellenius AC: Metabolic adaptation to reduced muscle blood flow. I. Enzyme and metabolite alterations. Am J Physiol 1985, 249:E63-9

3. Hoppeler H, Hudlicka O, Uhlmann E, Claasen H: Skeletal muscle adaptations to ischemia and severe exercise. Clin J Sport Med |992, 2:43-5 |

4. Perry MO, Fantini G: Ischemia: Profile of an enemy. J Vasc Surg 1987, 6:231-4

5. Perry MO: Historical Perspective. In: Ischemia-Reperfusion Injury of skeletal Muscle 1994, I-4

6. Eklof B, Neglen $\mathrm{P}$, Thompson $\mathrm{D}$ : Temporary incomplete ischemia of the legs induced by aortic clamping in man. Ann Surg 1981, 93:89-98

7. Malan E, Tatoni G: Physio-and Anato-pathology of acute ischemia of the extremities. I Cardiovasc Surg 1963, 4:2-10

8. Sjøstrøm M, Angquist KA, Rais O: Intermittent claudication and muscle fibre fine structure: Correlation between clinical and morphological data. Ultrastruct Pathol 1980, I:309-26

9. England JD, Regensteiner JG, Ringel SD, Carry MR, Hiatt WR: Muscle denervation in peripheral occlusive arterial disease. Neurology 1992, 42:994-9

10. Bylund AC, Hammarsten J, Holm J, Schersten T: Enzyme activities in skeletal muscles from patients with peripheral arterial insufficiency. Eur J Clin Invest 1976, 6:425-9

II. Janssen E, Johansson J, Sylven C, Kaijer L: Calf muscle adaptation in intermittent claudication. Side-differences in muscle met- abolic characteristics in patients with unilateral arterial disease. Clin Physiol 1 988, 4 I 7:67-72

12. Lundgren F, Dahllof AG, Schersten T, Bylund-Fellenius AC: Muscle enzyme adaptation in patients with peripheral arterial insufficiency: spontaneous adaptation, effect of different treatments and consequences on walking performance. Clin Sci 1988, 77:485-93

13. Henriksson J, Nygaard E, Andersson J, Eklof B: Enzyme activities, fibre types and capillarization in calf muscles of patients with intermittent claudication. Scand J Clin Lab Invest 1980, 40:36 I-369

14. Regensteiner JG, Wolfel EE, Brass EP, Carry MR, Ringel SP, Hargarten ME, Stamm ER, Hiatt WR: Chronic changes in skeletal muscle histology and function in peripheral occlusive arterial disease. Circulation 1993, 87:413-21

15. Hegstad AC, Ytrehus K, Lindal S, Myklebust R, Jorgensen L: The initial phase of myocardial reperfusion is not associated with aggravation of ischemic-induced ultrastructural alterations in isolated rat hearts exposed to prolonged global ischemia. Ultrastruct Pathol 1999, 23(2):93-105

16. Welt K, Fitzl G, Mark B: Lipoxygenase inhibitor FLM an effective protectant of myocardial micro vessels against ischemia-reperfusion injury? An ultrastructural-morphometric study. Exp Toxicol Pathol 2000, 52(I):27-36

17. Del Maestro RF: An approach to free radicals in medicine and biology. Acta Physiol Scand Suppl 1980, 492:153-68

18. Granger DN: Role of xanthine oxidase and granulocytes in ischemia-reperfusion injury. Am J Physiol. 1988, 255:HI269-75

19. McCord JM: Oxygen-derived free radicals in postischemic tissue injury. $N$ Engl J Med 1985, 3 I 2:159-63

20. Davis JM, Fantini GA: Remote effects. In: Ischemia-Reperfusion Injury of skeletal Muscle. 1994, I-4

21. Welbourn CR, Goldman G, Paterson IS, Valeri CR, Sherpo D, Heehtman HB: Pathophysiology of ischemia reperfusion injury: central role of the neutrophil. $\mathrm{Br}$ J Surg |99|, 78:65|-5

22. Dubowitz V, Brooke MA: Muscle Biopsy: A modern Approach. 1985, 533

23. Nemeth P, Pette D, Vrbova G: Comparison of enzyme activities among single muscle fibres within defined motor units. J Physiol Lond 1981, 3 I I:489-95

24. Jakobsson F, Borg K, Edstrom L, Grimby L: Use of motor units in relation to muscle fibre type and size in man. Muscle \& Nerve 1988, I I:121|-8

25. Angquist KA, Sjøstrøm M: Intermittent claudication and muscle fibre fine structure: Morphometric data on mitochondrial volumes. Ultrastruct Pathol 1980, I:461-70

26. Friden J, Sfakianos PN, Hargens AR, Akeson WH: Residual muscular swelling after repetitive eccentric contractions. J Orthop Res 1988, 6:493-8

27. England JD, Ferguson MA, Hiatt WR, Regensteiner JG: Progression of neuropathy in peripheral occlusive arterial disease. Muscle \& Nerve 1995, 1 8:380-7

28. Badier M, Guillot C, Laggier-Tessonnier F, Jammes Y: EMG changes in respiratory and skeletal muscles during isometric contraction under normoxic, hypoxemic, or ischemic conditions. Muscle \& Nerve 1994, 1 7:500-8

29. Chervu A, Moore WS, Hosher E, Quinones-Baldrich WJ: Differential recovery of skeletal muscle and peripheral nerve function after ischemia and reperfusion. J Surg Res 1989, 47:12-19

30. Christ F, Moser CM, Niklas M, Gartside IB, Gamble J, Refior HJ, Peter $\mathrm{K}$, Messmer K: Prevalence of cyclic changes in limb volume (volumotion) of male patients with knee injury and the effects of ischemia/reperfusion due to tourniquet. Int J Microcirc Clin Esep 1995, I 5: 14-20

31. Lundborg G: Ischemic nerve injury: Experimental studies on intraneural micro vascular pathophysiology and nerve function in a limb subjected to temporary circulatory arrest. Scand J Plast Reconstr Surg Suppl 1970, 6:3-113

32. Zollman PJ, Awad O, Schmelzer JD, Low PA: Effect of ischemia and reperfusion in vivo on energy metabolism of rat sciatictibial and caudal nerves. Exp Neurol I99I, I I 4:3 I5-20

33. Karpati G, Carpenter S, Melmed C, Eisen AA: Experimental Ischemic Myopathy. I Neurol Sci 1974, 23: I29-6I

34. Henliksson-Larsen KB, Lexell J, Sjøstrøm M: Distribution of different fibre types in human skeletal muscles. I. Method for the preparation and analysis of cross sections of whole human tibialis anterior muscles. Histochem J 1983, I 5: 167-78 
35. Albani M, Kiskinis D, Natsis K, Megalopoulos A, Gigis P, Guiba-Tziampiri $O$ : Histochemical and ultrastructural characteristics of leg muscle fibres in patients with repairative abdominal aortic aneurysm (AAA). Anat $\operatorname{Rec} 2000,260: 1-15$

36. Jennische E: Ischaemia-induced injury in glycogen-depleted skeletal muscle. Selective vulnerability of FG-fibres. Acta Physiol Scand 1985, I 25:727-34

37. Blebea J, Kerr JC, Shumko JZ, Feinberg RN, Hobson RW: Quantitative histochemical evaluation of skeletal muscle ischemia and reperfusion injury. J Surg Res 1987, 43:3II-2I

38. Clyne AC, Mears H, Weller RO, O'Donnell TF: Calf muscle adaptation to peripheral vascular disease. Cardiovasc Res 1985, 19:507-5/2

Publish with BioMed Central and every scientist can read your work free of charge

"BioMedcentral will be the most significant development for disseminating the results of biomedical research in our lifetime."

Paul Nurse, Director-General, Imperial Cancer Research Fund

Publish with BMC and your research papers will be:

- available free of charge to the entire biomedical community

- peer reviewed and published immediately upon acceptance

- cited in PubMed and archived on PubMed Central

- yours - you keep the copyright 